RESUMEN: El artículo expone los rasgos generales de la idea de la universidad según el cardenal John Henry Newman, acentuando su concepto de educación liberal como término medio entre la educación confesional y la educación meramente pragmática. La educación liberal es libre y entraña la formación del intelecto, para que busque en todo momento la verdad y la realice. El artículo concluye señalando algunas semejanzas entre el pensamiento de Newman y el Departamento de Estudios Generales del ITAM.

PALABRAS CLAVE: John Henry Newman, universidad, educación liberal, estudios generales.
ABSTRACT: In this article, we will explore the main characteristics of Cardinal John Henry Newman's idea of a university, emphasizing his notion of liberal education as in between a moral and a pragmatic education. Liberal education is free and trains a person's intellect to constantly pursue the truth. Finally, this article showcases the similarities between his thought and that of ITAM's General Studies Department.

KEYWORDS: John Henry Newman, university, liberal education, General Studies. 


\section{JOHN HENRY NEWMAN Y LA IDEA DE LA UNIVERSIDAD}

\section{Introducción}

La serie de conferencias reunidas bajo el titulo de "Idea de la Universidad" tiene una historia bastante peculiar. Fueron pronunciadas en 1852 durante el proceso de fundación de la universidad católica de Irlanda.

${ }^{1}$ Newman consideró esta obra como una de sus principales. Según él, a lo largo de su vida sólo escribió cinco obras "constructivas": el oficio profético, el ensayo sobre la justificación, el ensayo sobre la doctrina del desarrollo, el ensayo en ayuda de una gramática del asentimiento y la idea de la universidad. Cfr. Ian Ker, John Henry Newman, una biografia, 2010, Madrid, Palabra, p. 642. En cuanto al estilo y contenido, "Newman consideraba en lo que habría de ser la primera mitad de su clásico Idea of a University, que era uno de 'mis dos trabajos mejor acabados, desde el punto de vista artístico', pero también el que lo había metido en 'mayores' aprietos, en comparación con las demás publicaciones. Present Position of Catholics in England había sido el más fácil de escribir", ibid., p. 395.
Pero el orador no era irlandés, sino inglés y tenía ¡apenas! unos cuantos años de ser católico, pues recién en 1845 se había convertido al catolicismo, después de años de fecunda labor en el seno de la Iglesia anglicana. El orador era un sacerdote perteneciente al Oratorio de san Felipe Neri, el cual después llegaría a ser Cardenal y, recientemente, el 19 de septiembre de 2010, ha sido inscrito en el libro de los beatos de la Iglesia Católica. La importancia de estas observaciones radica en el hecho de que las conferencias pronunciadas, lejos de encerrarse en el marco de la situación política entre ingleses e irlandeses o entre anglicanos y cató- 
licos, ofrece una visión de la educación universitaria que podríamos llamar perenne y siempre actual, como tendremos ocasión de ver.

A Newman no le era desconocido el ambiente universitario: formado en el Trinity College de Oxford, llegó a ser Fellow y posteriormente Tutor del Oriel College, el más famoso entre los Colleges de Oxford en su tiempo y santuario intelectual de la religión anglicana. Precisamente en Oriel, Newman experimenta la fuerte presión que ejerce el credo anglicano en la educación superior, no sólo por el hecho de que cualquiera que deseara estudiar allí tenía que firmar los 39 artículos de la profesión de fe anglicana, sino porque también determinaba el contenido y la orientación de las clases y de la investigación.

Por el otro lado, al volverse católico, Newman vio la profunda necesidad de educación superior de los católicos ${ }^{2}$ y el callejón sin salida en que se encontraban, pues los jóvenes católicos sólo tenían dos opciones:

${ }^{2}$ Newman escribe en 1863: "Pues bien, como del principio al fin, mis intereses se han dirigido a la educación". Y explica lo que entiende por ello: "tratar de mejorar la condición, el ambiente de los católicos, mediante un examen de los fundamentos que sirven de base a sus argumentos y a su posición con respecto a la filosofía y a la situación del mundo actual, mediante la presentación de una visión más justa y mediante la ampliación y refinamiento de sus mentes, en una palabra, educándolos", John Henry Newman, Escritos autobiográficos, 1962, Madrid, Taurus, p. 220. ir a las universidades anglicanas (al momento ya podían hacerlo) o ir a las universidades civiles, con marcado acento ateo (como la recién fundada universidad de Londres o el Queens College de Irlanda). ${ }^{3}$ Esta situación podría hacer pensar que Newman o cualquier otro pensador, al inaugurar una universidad católica, imprimiría un fuerte tinte confesional, casi apologético, para afianzarse en su identidad. Pero Newman no consideró que fuera ese el camino correcto. Cuando fue invitado a participar en la fundación de la universidad, el Papa y los obispos irlandeses tenían en mente seguir el ejemplo de la famosa universidad de Lovaina, la cual fue determinante en el aggiornamento de la filosofía escolástica a finales del siglo XIX. En este contexto, Newman pronuncia la serie de discursos que conocemos como "Idea de la universidad", en los cuales expone su concepto de educación liberal.

Pero antes de explicar este concepto, es muy necesario que refiramos qué entiende Newman por Universidad.

${ }^{3}$ En 1845 , el primer ministro Robert Peel estableció la no confesional Queen's University de Irlanda como alternativa al anglicano Trinity College de Dublín. Este esquema recibió el nombre de "educación mixta" y contó con la aprobación de pocos obispos irlandeses, al tiempo que Roma prohibió en reiteradas ocasiones a la iglesia irlandesa acudir a esa universidad. Cfr. Ian Ker, "Editor's Introduction", en John Henry Newman, The Idea of a University, 1976, Oxford, Clarendon Press, p. xiii. 


\section{¿Qué es una universidad?}

Sin cuestionarse otros posibles orígenes del término universidad (entre los cuales estaría el famoso Studium Generale, bastante significativo para nuestro departamento aquí en el ITAM),${ }^{4}$ Newman hace derivar la palabra universidad de la totalidad del saber: "la Universidad es un lugar que enseña saber universal". ${ }^{5}$ Newman enfatiza las palabras saber y enseñar, que modo que, en su comprensión, la misión primera (no exclusiva) de la universidad es intelectual, no moral, ni religiosa, pero tampoco utilitaria profesional, al tiempo que su labor primera (no exclusiva) es difundir y extender el saber, no hacerlo progresar mediante la investigación, pues esa labor pertenece a las Academias, Sociedades o Asociaciones de investigación de un saber determinado.

La argumentación de Newman es la siguiente: "la verdad es el obje-

${ }^{4} \mathrm{Al}$ respecto, Jorge Rodríguez señala que “este concepto [Estudios Generales], además, nos vincula históricamente con el momento fundacional de la institución universitaria en Europa y con el ideal humanista que se fue afirmando en esas universidades... se designaba Studium Generale a una institución de educación superior cuando alcanzaba reconocimiento internacional y combinaba las artes liberales con alguna especialidad (que eran teología, derecho y medicina). Jorge Rodríguez Beruff, "El papel de los estudios generales", en Estudios ITAM 97 (2011), p. 22.

${ }^{5}$ John Henry Newman, Discursos sobre el fin y la naturaleza de la educación universitaria, 1996, Pamplona, traducción, introducción y notas de José Morales, EUNSA, p. 27. to propio de cualquier tipo de conocimiento", 6 pues la verdad se refiere a los hechos y sus relaciones y el conocimiento es la aprehensión de esos hechos y esas relaciones. Pero el conjunto de estos hechos y relaciones es tan vasto que la mente humana no puede abarcarlo con una simple mirada y apropiarse de él definitivamente. En lugar de ello, "por grados y por aproximaciones circulares se eleva la mente para hacerse con un cierto conocimiento de ese universo en el que ha nacido". ${ }^{7}$ Las resultantes vistas parciales o formalizaciones del intelecto respecto del objeto constituyen las ciencias, las cuales abarcan mayores o menores parcelas de la realidad. Así, "en la medida en que las ciencias son formas de conocimiento, capacitan al intelecto para dominarlo e incrementarlo; y en la medida en que son instrumentos, le permiten comunicarlo fácilmente a otros". ${ }^{8} \mathrm{De}$ ahí para Newman sea claro que las ciencias procedan a partir del principio, operativo no real, de la división del trabajo. Esto hace que las ciencias difieran en importancia, al tiempo que necesiten de apoyo externo por su carácter provisional e incompleto. Vistas en conjunto, "las ciencias se aproximan a (ser) una representación o reflexión subjetiva de la verdad objetiva". ${ }^{9}$

\footnotetext{
${ }^{6}$ Ibid., p. 76

${ }^{7}$ Ibid., p. 77.

${ }^{8}$ Ibid., p. 78

${ }^{9} \mathrm{Ibid}$., p. 78.
} 
La universidad es el lugar donde todos los saberes tiene su lugar (Newman es sumamente explícito en la defensa de todas y cada una de las áreas del saber). De manera obvia, señala la necesidad de la teología dentro de la universidad, pero lo mismo hace con la física, la economía o la sociología; una universidad que no permita todos los saberes se descalifica automáticamente como tal. Ahora bien, la universidad no sólo es el lugar físico donde se reúnen los cultivadores de las diferentes ciencias, a manera de una posada donde todo peregrino puede llegar a guarecerse con seguridad. La universidad es tal porque es el lugar donde las diferentes ciencias entran en relación unas con otras, se vislumbra su jerarquía, se cuidan sus campos de acción, se defienden sus respectivos métodos, pero también se señalan sus límites, de modo que ninguna ciencia rebase el campo que le corresponde y se entrometa en otro, o que alguna extienda su método a las demás, asegurando que es el único posible. La universidad es el lugar donde las ciencias conviven en orden y armonía unas con otras, teniendo como árbitro y juez la verdad. Newman utiliza una imagen sugerente y precisa sobre la función de la universidad cuando escribe:

Lo que representa un imperio en la historia política es lo que represen- ta una Universidad en el campo de la filosofía y de la investigación [...] actúa como árbitro entre una verdad $y$ otra $[\ldots]$ no mantiene una sola y exclusiva línea de pensamiento [...] es imparcial hacia todas y promueve cada una en el lugar que le corresponde en el cumplimiento de su propio objetivo. ${ }^{10}$

Detrás de esta idea de universidad subyace un presupuesto fundamental del pensamiento de John Henry Newman: la idea de que el mundo (entendido como la totalidad del saber) es admirablemente amplio en cuanto a los objetos por conocer y no puede ser abarcado completamente. De ahí que cada ciencia represente sólo una perspectiva de esa totalidad, que necesariamente está orientada a complementarse con las que ofrecen las demás ciencias. A su vez, la idea de que el hombre tiene la maravillosa capacidad de conocer, escudriñar, ordenar, jerarquizar el mundo, pero al mismo tiempo la fragilidad y limitación de esta capacidad de conocer. Es decir, el hombre puede conocerlo todo, pero nunca en su totalidad y de manera definitiva. Por ello, las diferentes ciencias, en cuanto construcciones del sujeto humano, representan los diferentes ángulos con los cuales el hombre intenta abarcar la totalidad

\footnotetext{
${ }^{10}$ John Henry Newman, Cristianismo y ciencias en la Universidad, 2011, Pamplona, Eunsa, pp. 41-2.
} 
del mundo. La universidad, en tanto conjunto ordenado y jerarquizado de todos los saberes, es un reflejo directo y subjetivo del mundo objetivo conocido por el hombre. Por ello, si no están incluidas todas las ciencias, no podemos decir que hemos conocido el mundo en su totalidad y, por ello, también resulta claro que si alguna ciencia intenta abarcarlo todo, sin tener en cuenta a las demás, es porque ingenua o soberbiamente quiere ir más allá de los límites que por el lado de la cosa y por el lado del sujeto cognoscente se le imponen. A partir de lo anterior, se entiende la necesidad del diálogo y la confrontación como algo propio y natural del ambiente universitario, pues, como afirma Roman Siebenrock "es claro que el portador de esta idea [de la totalidad del saber] no es un individuo, sino una comunidad de comunicación, que en la idea de la universidad encuentra su adecuado campo de acción". ${ }^{11}$ Newman, pues, entiende la universidad como el lugar del intercambio vivo y actual de los científicos entre sí y con la comunidad universitaria (los estudiantes), ${ }^{12} \mathrm{de}$

${ }^{11}$ Roman Siebenrock, Wahrheit, Gewissen und Geschichte. Eine systematisch-theologische Rekonstruktion des Wirkens John Henry Kardinal Newmans, 1996, Sigmaringendorf, Regio Verlag Glock und Lutz, p. 444.

${ }^{12}$ Sobre la importancia del diálogo en las materias de estudios generales, $c f r$. el artículo de Carlos de la Isla, "Reflexiones sobre el método dialógico", Estudios, vol. II, núm. 70, otoño 2004, pp. 7-19. modo que se dé el avance de cada una de las ciencias en diálogo y confrontación con las demás, y buscando siempre nuevamente la mejor integración entre ellas, de manera que se alcance siempre provisionalmente la totalidad del saber, pues aunque el espíritu humano es finito, tiende de suyo al saber universal y a la verdad universal. Nuevamente en palabras de Siebenrock:

La verdad total es posible únicamente a través del intercambio, el diálogo, la controversia y la rivalidad en la "science community". Por ello la verdad universal no es posesión inmediata de un individuo o de una disciplina, sino que se expresa cada vez nuevamente en la comunidad de comunicación como resultado y condición de la universidad. ${ }^{13}$

Ahondando un poco más en esta cuestión, otro gran conocedor alemán de Newman, Günter Biemer, señala que para Newman este intercambio interpersonal y vivo es mucho más importante y efectivo que los libros, y cita un consejo de Newman al respecto "cuando queremos ser formados de manera completa y exacta en un ámbito del saber, el cual es complicado y diferenciado, debemos preguntar a los hombres vivos y escuchar su voz viviente". ${ }^{14}$

${ }^{13}$ Siebenrock, op. cit., p. 445.

${ }^{14}$ Günter Biemer, Die Wahrheit wird stärker sein. Das Leben Kardinal Newmans, 2002, Frankfurt a.M., Peter Lang Verlag, pp. 266-7. 
Lo anterior nos ha mostrado la universidad como un lugar con un ambiente muy específico, el cual, por cierto, no es nada fácil de lograr: diálogo, confrontación, comunicación, relación interpersonal. La capacidad para realizar estas acciones es fruto de la meta de la universidad, a saber: de la educación liberal.

\section{Educación liberal ${ }^{15}$}

En primer lugar, se da una concepción negativa, es decir, se define por sus opuestos. Y es que Newman, fuertemente influenciado por Aristóteles, ${ }^{16}$ concibe la educación liberal como el medio virtuoso entre dos extremos viciosos: la educación liberal no es una educación confesional (pues la teología debe tener su lugar en la universidad, pero no puede en-

${ }^{15}$ Es muy importante distinguir claramente en Newman su concepto de educación liberal del liberalismo, contra el cual luchó prácticamente toda su vida. En su discurso de recepción del cardenalato, Newman escribe lo siguiente: "me alegra decir que desde el principio me he opuesto a un gran mal. Por espacio de 30, 40, 50 años he resistido con mis mejores energías el espíritu del liberalismo en religión [...] El liberalismo en religión es la doctrina según la cual no existe una verdad positiva en el ámbito religioso sino que cualquier credo es tan bueno como otro cualquiera", "Biglietto Speech", en John Henry Newman, Cartas y diarios, 1996, Madrid, Rialp, pp. 161-2.

${ }^{16}$ Siebenrock sostiene que los discursos sobre la universidad pueden ser interpretados como el programa que el Estagirita establecía con su filosofía primera. Cfr. Siebenrock, op. cit., pp. 446-50. trometerse legítimamente en los asuntos de las otras ciencias), ${ }^{17}$ pero tampoco es una educación meramente pragmática, encargada de formar profesionales de las respectivas ciencias y nada más. En cuanto que no está atada ni a la religión ni a los intereses inmediatos de la profesión, Newman llama a esta educación, como ya lo hiciera Aristóteles respecto de la filosofía primera, libre, liberal. ${ }^{18}$ Según Aristóteles, lo liberal se opone a lo servil (trabajo físico) por lo que la educación liberal o actividades liberales son ejercicios de la mente, de la razón y de la reflexión. ${ }^{19}$ Además, siempre siguiendo a Aristóteles, las posesiones liberales se oponen a las útiles en que son disfrutables, es decir, no se percibe ninguna ganancia, sino que se disfruta el solo uso en sí mismo.

En cuanto al contenido de la educación liberal, Newman precisa:

Su misión [de la universidad] consiste en la formación del intelecto. No necesita dar más a sus estudiantes.

${ }^{17}$ Esta afirmación habría de ser matizada para evitar malos entendidos.

${ }^{18}$ Que Newman tenía una altísima estima por el Estagirita lo demuestran las siguientes palabras: "Mientras seamos hombres no podremos evitar ser, en gran medida, aristotélicos, porque el gran Maestro no hace sino analizar las ideas, sentimientos, percepciones y opiniones de la humanidad [...] En muchos asuntos, pensar correctamente es pensar como Aristóteles, y somos sus discípulos lo queramos o no, aunque no lo sepamos", Newman, Discursos, op. cit., p. 132.

${ }^{19}$ Ibid., p. 125. 
Ha cumplido su obra, cuando ha hecho esto. La universidad educa el intelecto para que razone bien en todos los temas, para que tienda hacia la verdad y la asimile. ${ }^{20}$

La educación liberal es aquella que forma el intelecto. Para entender esto, tengamos en cuenta lo que Newman ha mencionado sobre la formación de las ciencias. Dado que las ciencias son formalizaciones del saber sobre un campo determinado, y se relacionan unas con otras, es necesario ver y reconocer el valor de cada una y la jerarquía que guardan unas sobre otras. Pero esto no puede ser labor de una ciencia junto con otras tareas. Aristóteles asignaba a las ciencias superiores el nombre de arquitectónicas y de entre ellas señaló una como la primera en absoluto: la filosofía primera. Por tener un punto de vista superior, el del ente en cuanto ente, podía erigirse como fundamento de todas las demás. Newman comparte el punto de vista del Estagirita pero lo aplica de una manera original: en lugar de reservarle a una ciencia en específico la labor de discernimiento entre los diferentes campos del saber, Newman considera que la universidad debe formar en todos sus integrantes un hábito mental, que precisamente por sus pretensiones llama "filosófico", el cual no es posesión exclusiva de

${ }^{20}$ Ibid., p. 144. los cultivadores de una ciencia, sino una posible adquisición de todo ser humano. En sus palabras:

La comprehensión del influjo de una ciencia sobre otra, y el uso que cada una hace de las demás, así como la situación, la limitación, el ajuste y la debida apreciación del conjunto pertenece, a mi juicio, a un tipo de ciencia diferente de todas las demás, una especie de ciencia de las ciencias, que es mi idea de la filosofía en el verdadero sentido de la palabra, y pertenece también a un hábito filosófico de la mente, que en estos discursos denominaré con ese nombre. ${ }^{21}$

Digamos que Newman democratiza la más bien aristocrática ciencia primera de Aristóteles. Pero veamos con más detenimiento en qué consiste ese hábito mental llamado filosófico, que es lo propio de la educación liberal.

La formación o enseñanza universitaria no va encaminada solamente a un saber puntual y específico de cada ciencia, sino a un "crecimiento y ejercitación en ciertos hábitos morales e intelectuales". ${ }^{22}$ La educación liberal no está orientada principalmente a los contenidos, sino a la "educación del intelecto", ${ }^{23}$ que

\footnotetext{
${ }^{21}$ Ibid., 81.

${ }^{22}$ Ibid., p. 29.

${ }^{23}$ Ibid., p. 33.
} 
Newman describe de la siguiente manera:

Aquí buscamos la fuerza, la solidez, el estilo abarcante y la versatilidad del intelecto, el dominio sobre nuestras potencias anímicas, la justa estimación instintiva de las cosas que desfilan ante nosotros, que a veces es un don natural, pero que generalmente no se logra sin esfuerzo y el ejercicio de los años. ${ }^{24}$

Newman es consciente que la mayoría de los jóvenes no poseen esta capacidad para captar las consecuencias de las ideas y de las acciones, sino que más bien son deslumbrados por las apariencias. Por ello considera fundamental como "primer paso" "inculcar en la mente de un joven las ideas de ciencia, método, orden, principio y sistema, así como el de regla y excepción, de riqueza y armonía". ${ }^{25}$

Tales principios deben ser ejercitados una y otra vez, con esfuerzo, dedicación y paciencia, siguiendo la idea clásica de que un hábito es la repetición constante de actos. En palabras de Newman:

se forma con ella [la educación liberal] un hábito de la mente que dura toda la vida, y cuyas características son la libertad, el sentido de justicia, serenidad, moderación y sabiduría. Es en suma, lo que en un discurso ante-

${ }^{24}$ Ibidem.

${ }^{25}$ Ibid., p. 35. rior me he atrevido a denominar hábito filosófico. Esto es lo que considero el fruto singular de la educación suministrada en una universidad... Este es el fin principal de una universidad en el trato con sus estudiantes. $^{26}$

La universidad es, pues, el lugar del saber universal y de su comunicación interpersonal. Pero esto no significa que el alumno tenga que saber todo de todas las ciencias. Sin embargo, la universidad le da la ventaja de ver a aquellos que si practican esas ciencias y así el alumno aprende a respetar, a tener en cuenta a las otras ciencias y a ayudarse unos a otros. El que estudia en una universidad se beneficia de la tradición intelectual, al entender las grandes líneas del saber, los principios en que descansa, las relaciones que guardan unas con otras y sus mutuas limitaciones. "Se trata de la acción de un poder formativo que produce orden y da sentido a la materia de nuestras adquisiciones intelectuales" 27 . Hoy diríamos simplemente que se trata de formación, más que de mera información. O bien de formar en los estudiantes el pensamiento reflexivo y crítico. ${ }^{28}$ Se trata de criterios de jui-

${ }^{26}$ Ibid., 125.

${ }^{27}$ Ibid., p. 151.

${ }^{28} \mathrm{Al}$ respecto, la siguiente afirmación: "una educación que promueva en los sujetos la reflexividad propia de la educación general conlleva el germen de la libertad, al permitirles adueñarse de 
cio y acción aplicables a cualquier situación y contenido. Para Newman, un hombre que lee el periódico es un hombre bien informado, pero nunca un hombre de cultura intelectual.

Ahora bien, esta formación del intelecto es buena por sí misma, puesto que es la perfección del intelecto y toda perfección es un bien. Pero no es un bien instrumental, en el sentido de que sirva para otra cosa, sino que puede descansar en sí mismo. "La educación liberal, considerada en sí misma, es sencillamente el cultivo del intelecto como tal, y que su objeto es, ni más ni menos, la excelencia intelectual". ${ }^{29}$ Pero al mismo tiempo, siguiendo la terminología clásica, Newman sostiene que el bien es difusivo de suyo y el bien se comunica naturalmente; por ello, el bien puede ser útil, mientras que lo útil no tiene que ser necesariamente bueno. Así, bien entendido, el saber en sí mismo puede ser útil:

No digo útil en sentido vulgar, mecánico y mercantil, sino como un bien que se difunde, o una bendición, o un don, un poder o un tesoro, pri-

su historia y de las consecuencias de sus acciones, de lo que es de vital importancia para una cultura comprometida con la justicia". Me parece que Ana Margarita Haché explica en palabras actuales lo que Newman entiende por educación liberal, $c f$ r. "El papel de la educación general en los estudios universitarios contemporáneos", en Estudios, vol. IX, núm. 97, verano 2011, p. 11.

${ }^{29}$ Newman, Discursos..., op. cit., p. 141. mero para quien lo posee, y a través de él para el mundo entero. Si una educación liberal es buena, debe necesariamente ser también útil. ${ }^{30}$

Una vez formado el intelecto, puede darse luego su ampliación por el saber (hechos), siguiendo el adagio latino quidquid recipitur ad modum recipientis recipitur. $*$ Es decir, si se tiene el hábito filosófico de la mente, los conocimientos que se adquieran tendrán siempre su lugar, orden y valor, de modo que la educación no sea sólo acumulación de conocimientos, sino verdadera asimilación de los mismos. La transmisión de conocimientos es medio, no fin de la educación liberal. No se trata del saber de cosas aisladas, sino la mutua relación entre ellas. "Educación es una palabra mayor, es la preparación para el saber, y la enseñanza de conocimientos en orden a esa preparación". ${ }^{31} \mathrm{Y}$ en otro lugar: “educación es una palabra más elevada. Implica una acción que afecta a nuestra naturaleza intelectual y a la formación del carácter. Es algo individual y permanente". ${ }^{32}$

Newman fue siempre muy afecto a buscar imágenes concretas de aquello que quería decir. La encarnación

*“Aquello recibido,se recibe según el modo del receptor". Más que adagio, parece un prinicio tomista (cfr. Summa Th. 1a, q. 75 a.5; 3a, q.5) [N. del E.].

${ }^{30}$ Ibid., p. 176.

${ }^{31}$ Ibid., p. 159.

${ }^{32}$ Ibid., p. 135. 
del intelecto formado, la imagen concreta de aquel que ha adquirido el hábito filosófico que pretende la educación liberal es el Gentleman. ${ }^{33} \mathrm{Su}$ definición-descripción es bien conocida en sus rasgos generales:

El caballero es aquel que nunca inflige dolor, evita lo que pueda causar estridencia o sobresalto en la mente de los demás, evita todo enfrentamiento de opiniones, se preocupa por que todos se hallen a gusto, es afectuoso con todos, sabe con quién y de qué habla, interpreta todo favorablemente, no es mezquino en sus discusiones, es prudente y tiene buen sentido, nunca es injusto, es sencillo y sólido, breve y eficaz. Respeta la piedad y la devoción, es amigo de la tolerancia [...] estos son algunos de los rasgos del carácter ético formado por un intelecto cultivado, al margen de principios religiosos. ${ }^{34}$

Con todo, Newman es coherente al precisar que la educación podría ser una buena preparación para el nivel religioso de la fe, pero no lo incluye. La educación es un bien natural, mientras que la fe es un bien sobrenatural. La frase de Newman es contundente: "la educación liberal no hace al cristiano, ni al católico, sino al caballero". ${ }^{35}$

\footnotetext{
${ }^{33}$ Rosario Athié Lambarri prefiere hablar de gentleperson para incluir ambos sexos.

${ }^{34}$ Cfr. Newman, Discursos..., pp. 210-212.

${ }^{35}$ Ibid., p. 140.
}

\section{Newman y los estudios generales}

Quiero presentar una concreción del pensamiento de Newman, que puede resultar muy interesante. En un discurso titulado "Cristianismo y literatura", Newman sostiene que "las materias de la escuela de filosofía y letras constituyen los estudios centrales en la universidad". Considero que los cursos de estudios generales cubren lo que Newman atribuye a la facultad de filosofía y letras. Carlos de la Isla, en su artículo "Reflexiones sobre el método dialéctico" recoge las palabras del entonces rector del ITAM, licenciado Javier Beristáin: "creo que las ventajas y real aceptación de nuestros egresados se deben principalmente a los estudios generales". ${ }^{36}$ ¿En que consiste esta valoración?

Para Newman, un hombre debe leer en el original a los autores griegos y latinos: "los clásicos [...] en la mayoría de los casos, siempre han sido los instrumentos de educación, adoptados por la civilización occidental". ${ }^{37}$ (Recuérdese que no se supone ninguna recepción pasiva, sino el vivo intercambio con el autor por medio del estudioso respectivo que dialoga y se confronta con los estudiantes). Al

\footnotetext{
${ }^{36}$ Carlos de la Isla, op. cit., p. 7.

${ }^{37}$ Newman, The Idea of a University, 1976, Oxford, Clarendon Press, p. 216.
} 
preguntar Newman por aquello que pueda "fortalecer, refinar y enriquecer mejor las capacidades intelectuales" responde con lo que muchos siglos de experiencia en Occidente han mostrado: "la concienzuda lectura de los poetas, historiadores y filósofos de Grecia y Roma lograrán este propósito, como lo ha demostrado la experiencia". ${ }^{38}$ La literatura es, para Newman, uno de los estudios más provechosos para la educación liberal. En su conferencia "Cristianismo y literatura" afirma que la civilización occidental tiene "sus principios comunes, visiones, enseñanza y especialmente sus libros", a los cuales llama simplemente "clásicos", pues éstos nos colocan en aquella vieja tradición, cuando "proseguimos aquellos augustos métodos para ensanchar la mente, cultivar el intelecto y refinar los sentimientos, en los cuales ha consistido siempre el proceso de civilización". ${ }^{39}$ Menciona con especial acento a Homero, pero recuerda que también "otros poetas fueron asociados con Homero en la tarea de la educación, tales como Hesíodo y los trágicos". ${ }^{40}$ Con el arribo de la retórica cobró importancia el estudio de la historia, "y enton-

${ }^{38}$ Ibid., p. 220.

${ }^{39}$ Ibid., p. 216.

${ }^{40}$ Ibid., p. 218. Por trágicos entiende, obviamente a Esquilo, Sófocles y Eurípides. ces las páginas de Tucidides llegaron a ser uno de los estudios especiales por los cuales Demóstenes llegó a ser el primer orador de Grecia". ${ }^{41} \mathrm{New}$ man agrega expresamente a Aristóteles, no podía faltar, y concluye declarando a los maestros de Occidente: "el mundo debía tener ciertos maestros intelectuales y no otros; Homero y Aristóteles, con los poetas y filósofos que los rodearon, hubieron de ser los maestros de todas las generaciones". ${ }^{42} \mathrm{Y}$ hace una comparación ciertamente discutible: "incluso en nuestros tiempos Shakespeare y Milton no son estudiados en nuestro curso de educación; pero los poemas de Virgilio y Horacio, como aquellos de Homero y los autores griegos antiguos, estuvieron en la mochila de los alumnos no mucho más de cien años después de haber sido escritos". ${ }^{43}$

\section{Conclusión}

Para concluir estas reflexiones, quiero subrayar la relevancia social de la universidad en el pensamiento del cardenal Newman. Y es que la universidad no puede quedarse replega-

${ }^{41}$ Ibid., p. 218.

${ }^{42}$ Ibid., p. 219.

${ }^{43}$ Ibidem. Con todo, Newman termina incluyendo como núcleos centrales de Occidente a Jerusalén, Atenas y Roma, cfr. ibid., p. 223. 
da sobre sí misma, ya que por esencia es un lugar de comunicación del saber universal. Tal comunicación del saber debe tener su concreta aplicación en los diferentes campos de la vida social. Newman escribe:

Cuando el intelecto ha sido debidamente entrenado y formado para lograr una visión coherente de las cosas, desplegará sus energías con mayor o menor eficacia, según su capacidad en el individuo. En el caso de la mayoría de los hombres, se suele manifestar en el buen sentido, la sobriedad de pensamiento, el tono razonable, la sencillez, el autodominio y la firmeza de concepciones que lo caracterizan [...] En todos será un don para entrar con relativa facilidad en cualquier tema de pensamiento y abordar con éxito cualquier ciencia o profesión. ${ }^{44}$

La universidad prepara para vivir y para vivir bien; precisamente por eso, su meta es la formación del intelecto y no solo la transmisión de conocimientos, de modo que los estudiantes puedan "cumplir mejor sus tareas en la vida, y hacer de ellos miembros más inteligentes, capaces y activos de la sociedad". ${ }^{45}$ Newman no teme caer en contradicción cuando afirma: "si debe asegurarse un fin práctico a los cursos universitarios, afirmo que es el formar buenos miembros de la sociedad. Su arte es el arte de la vida social, y su objetivo es la preparación para el mundo". ${ }^{46}$

Los conceptos compartidos en la idea de la universidad de Newman han sido criticados muchas veces como irrealizables. Pero Newman entendía la utopía como un ideal regulativo de las acciones humanas: su realización siempre se quedará atrás, pero considero que las reflexiones newmanianas siguen siendo una fuente de inspiración al nacer de una profunda introspección de la naturaleza humana. Muchas de sus intuiciones no pudieron ser realizadas como las concibió, pero son susceptibles de otras materializaciones. Estoy seguro de que más de unos de los conceptos de Newman están presentes y operativos en el caminar de algunas universidades. 
CITAM Derechos Reservados.

La reproducción total o parcial de este artículo se podrá hacer si el ITAM otorga la autorización previamente por escrito. 